\title{
The Effect of Age on the Gingival Crevicular Fluid Composition During Experimental Gingivitis. A Pilot Study
}

\author{
Lazaros Tsalikis*
}

Department of Preventive Dentistry, Periodontology and Implant Biology, Dental School Aristotle, University of Thessaloniki, Greece

\begin{abstract}
:
Background: Cytokines have been proposed as potentially useful diagnostic or prognostic markers of periodontal inflammation related alterations during the experimental gingivitis model. The role of ageing in periodontal disease needs further elucidation; therefore investigations of its influence on host response are needed.

Objective: To study the effect of age on interleukins IL -6, IL-8 and TNF-a levels in gingival crevicular fluid (GCF) and their correlations to clinical parameters during experimental gingivitis.

Materials and Methods: Five young subjects (20-22 years old) and five old subjects (61-65 years old), all periodontal healthy, participated in this clinical trial. A professional plaque control programme was undertaken to establish healthy gingival conditions at baseline. Plaque index (PI), gingival index (GI) were recorded at 60 sites at baseline, after 21 days of no oral hygiene and one week later after professional cleaning and reestablishment of oral hygiene procedures. A total of 180 samples were analyzed with ELISA for levels of IL -6, IL-8 and TNF-a in gingival crevicular fluid. The examination included the mesiobuccal sites of the Ramfjord teeth. Comparisons between and within groups were performed by non-parametric tests (Mann- Withney) and correlations were sought for with Wilcoxon test. Significance was set at $\mathrm{p}=0.05$.

Results: Results showed significant diferences between the two groups with regard to the plaque and bleeding scores and GCF volume, all of which proved to be more pronounced in old group. With respect to laboratory data, mean cytokine concentrations were in general lower in young group. TNF-a had a steady increase for the adults, which was found to be statistically significant between Days 0 and 21 , IL-8 showed a statistically significant decrease at Day 28 in the young group and finally IL-6 showed a fluctuation, which was totally adverse for the two groups at each time point.

Conclusion: Within the limitations of the present study, age cannot be identified as a factor that strongly affects the cytokine expression and fluctuations even in a well-controlled environment of inflammation, such as experimental gingivitis.
\end{abstract}

Key Words: Experimental gingivitis, gingival crevicular fluid, cytokines, age.

\section{INTRODUCTION}

Periodontal pathogenesis has been extensively reviewed and it is well documented that the presence of microbial plaque results in an increased host immune-inflammatory response. Among the most prominent of these characteristics is the excessive production of inflammatory cytokines (e.g. interleukins, tumor necrosis factor-a). The inflammatory host response is nowadays accepted as the core aspect of periodontal disease [1] and these pro-inflammatory mediators are responsible for most of the periodontal breakdown occurring subclinically before the development of clinical symptoms. It is this response, rather than toxic products from putative periodontal pathogens, which is thought to be the direct cause of periodontal breakdown [1]. As a consequence, basic and clinical periodontal research have focused over the last decades on the host immune response to periodontal

*Address correspondence to this author at the 30 Agias Sofias str. Thesaloniki, 54622, Greece; Tel: 00302310276276; Fax: 00302310999613; E-mail: tsalikis@dent.auth.gr micro-organisms. Additionally, it has been hypothesized that even more crucial than the levels of each inflammatory mediator in the periodontal tissues is the relative balance between pro-inflammatory and anti-inflammatory cytokines and enzymes [2].

One model studied extensively in this context is the experimental gingivitis model. In this model, perfect oral cleanliness and gingival health is established first; then oral hygiene procedures are abandoned for a three week period, inducing gingivitis. The model, originally developed in the previous century by Loe et al. [3] has been employed by an increasing number of researchers to achieve a better understanding of the host's immune response to periodontal bacteria under certain conditions [4] Experimental gingivitis is thus a well-controlled and frequently-analyzed condition that has increased understanding of the host's response to undisturbed de novo plaque formation and accumulation [5].

Among many inflammatory and immune mediators identified in gingival crevicular fluid (GCF), cytokines have attracted particular attention and are suspected of involvement in both inflammation-related alteration and repair of the 
periodontal tissues [4]. Certain cytokines have been proposed as potentially useful diagnostic or prognostic markers of periodontal destruction $[4,6]$. For example, site-specific increases of IL-1 $\beta$ were observed in untreated periodontitis [7] and in experimental gingivitis models [8]. It has also been reported that old and young subjects with initially normal gingiva present similar levels of IL-1a and IL-1 $\beta$. However, during a 3 week period without oral hygiene, both groups developed increased levels of IL-1a, whereas IL-1 $\beta$ levels increased only in the old adult group indicating that there are differences between the inflammatory responses in young and old adult individuals [9]. Treatment of periodontitis resulted in a dramatic local decrease of IL-1 $\beta$, suggesting that this molecule is crucial in periodontal tissue destruction $[10,11]$.

Tumor necrosis factor-a, TNF-a, is a critical cytokine in the inflammatory response to infection [12]. Any genetic variability in the production of TNF-a after an infectious stimulus could have a significant impact on the degree of the inflammatory response and influence the clinical outcome [13]. TNF-a is a pleiotropic pro-inflammatory cytokine. A lot of organs are affected by the action of TNF-a; it conducts the neutrophils activation to inflammation but is also linked with their recession when it binds to the receptor TNF-R55 [14], TNF-a is produced by several cell types but primarily by the monocytes/macrophages; it affects lipid metabolism, relates to insulin resistance, blood coagulation, and endothelial activity. Low levels of TNF-a seem to be related to the preservation of homeostasis and to the remodeling/healing of damaged tissue through the activation and formation of fibroblasts [15].

Inteurleukin-6, (IL-6) is a pro-inflammatory cytokine, exuded by $\mathrm{T}$-cells and macrophages during immune response. Secretion of IL-6 is also observed from osteoblasts during their formation. It is one of the main mediators during acute immune response [16, 17]. The levels of IL-6 increase as the disease spreads. IL-6 activates the liver cells to produce CRP [16], while participating in bone resorption. The production of IL-6 activates osteoclast formation, facilitates bone resorption and T-cell differentiation [16-18].

Finally, Interleukin-8, (IL-8), has attracted particular interest because of its crucial role in the selective recruitment and activation of neutrophils $[19,20]$ and in routing them to the gingival sulcus. Both the concentration and total amount of IL-8 in GCF have been reported to correlate with the degree of inflammation [21-23].

Although many studies have worked on the roles of several inflammatory and immune mediators, especially of cytokines, only a few have investigated the involvement of predisposing factors in this immune response [9, 23, 24]. The factors controlled or measured and analyzed in these studies were: gender, smoking status, age and chronic gingivitis level [24]. To further elucidate the role of ageing in periodontal disease, investigations of its influence on host response are needed [9].

The aim of the present study was to investigate the effect of age on interleukins IL -6, IL-8 and TNF-a levels in gingival crevicular fluid (GCF) and their correlations to clinical parameters during experimental gingivitis. Clinical signs of gingivitis (gingival index and plaque index), gingival crevicular fluid volume and pro-inflammatory cytokines (TNF- a, IL-6 and IL-8) in gingival crevicular fluid were assessed at baseline through a period of 4 weeks including inflammation (Day 21) and recovery phase (Day28). The null hypothesis has been that age does not affect the above-mentioned parameters.

\section{MATERIALS AND METHODS}

\section{Experimental Design and Study Population}

The overall experimental design has been detailed previously [9]. The study was planned as a pilot trial. Five young adults ( 3 males and 2 females 20-22years old) and five old adults ( 3 males and 2 females 61-65 years old) clinically healthy non-smoking Caucasians were recruited for the study. Written informed consent was provided by all participants. The study design was approved by the local ethics committee and was deemed to conform to the guidelines issued in the Helsinki Declaration.

Each Volunteer Had to Fulfil the Following Criteria Be in good general health, not to have been exposed to antibiotic treatment in the previous 6 months, not to have been exposed to anti-inflammatory drugs therapy during previous month, have a healthy periodontium with no evidence of radiographic bone loss, presence of at least 20 teeth, attachment loss $<3 \mathrm{~mm}$, bleeding on probing $<10 \%$, plaque index $<20 \%$.

Exclusion criteria - applied either due to potential risks for the subjects during the experimental gingivitis period, or due to potential impacts on gingival health - were diseases of the immune system as well as known infections of any kind: diabetes; psychiatric diseases; drug abuse; nicotine consumption of more than five cigarettes per day; pregnancy; current orthodontic or dental treatments; untreated caries; defect fillings; inadequate dental restoration; probing depths above $3 \mathrm{~mm}$; major periodontal recessions (>2 $\mathrm{mm}$ and Miller, II, III and IV); regular use of calcium antagonists; anti-convulsants; immuno-stimulants or immunosuppressives prior to the study and any use of these substances from 1 week prior to the study until the end of the study; bleeding on probing at more than one site of intended measurement at the beginning of the study.

Six sites were selected in each patient for monitoring during the experimental gingivitis process, in particular the mesiobuccal sites of the Ramfjord teeth [16, 21, 24, 36, 41, 44]. A plaque control program, including prophylactic intervention, was undertaken prior to the start of the study: plaque and calculus was removed by using hand instruments, ultrasonic and polishing; all participants were instructed in how to maintain perfect oral hygiene so as to ensure gingival health at baseline (Day 0). At day 0, Plaque Index (Loe and Silness, 1963) [25], Gingival Index (Silness and Loe, 1964) [26] and GCF volume were assessed. After this, the participants were asked to refrain from any oral hygiene procedures for a period of three weeks. The patients were examined weekly to control compliance with this instruction and to observe if any visual signs of gingivitis, including redness 
and swelling had appeared. At Day 21, the same parameters were recorded. Thereafter the patients received a professionally performed prophylaxis and were asked to carry out oral hygiene procedures properly. One week later (Day 28) the patients were re-examined.

For the PI and GI scores full mouth records were obtained. The same examiner, who has been previously calibrated, undertook all clinical measurements. In order to determine the intraexaminer repeatability, two volunteers (one for each group) were clinically examined and the measurements were reassessed 60 minutes after the initial examination. The Kappa value was found to be 0.91 for the P1.I and 0.89 for the G.I. measurements. The gingival crevicular fluid collection was always performed prior to the clinical assessments and full mouth PLI and GI scores were obtained. The samples were obtained from the mesiobuccal sites of the Ramfjord teeth [16, 21, 24, 36, 41, 44]. Each site under study was isolated with cotton rolls and gently dried with a moisture free stream of air. Paper strips (Periopaper, Harco Electronics, CA) were inserted in the gingival crevice mesialbuccally for $30 \mathrm{sec}$. The GCF volume was determined by positioning the strips between the upper and the lower counterparts of the pre-calibrated Periotron 6000 (Oraflow). This instrument expresses GCF volume in IU linearly within the $0.0-1.5 \mu l$ range [27]. Strips visibly contaminated by bleeding were discarded. In that case the sample was retaken after 60 minutes. The paper strips were then placed in labelled test tubes containing $150 \mu \mathrm{l}$ PBST, frozen within 10 minutes and stored at $-70^{\circ} \mathrm{C}$ until dispatch to Hippocrates General Hospital of Thessaloniki for further processing. The Micro-Elisa method (R\& D) was used for measuring cytokines levels. All samples and standards were assayed in duplicate and the mean values at each time point were used to plot the respective graphs. Optical densities were determined using a reader with a $450 \mathrm{~nm}$ filter $(450 \mathrm{~nm}$ is the usual primary wavelength, use of a reference filter at $600-650 \mathrm{~nm}$ is recommended if it is available). The IL-6, IL- 8 and TNF-a levels were quantified using ELISA kits. Positive control samples confirmed the validity of each assay procedure and, using point/point paper liberalized standard curves and regression analysis, were applied to the point transformation. Thirty samples for every group at each time -point (a total of 180 samples) were analyzed for identification of TNF-a, IL-6 and IL-8.

\section{STATISTICAL ANALYSIS}

The available data were summarized using statistical descriptive indices of central tendency and dispersion (means, medians and std. deviations). A series of Non-Parametric tests was applied for hypothesis testing and statistical comparisons. More specifically the Mann-Whitney and the Wilcoxon tests were used in order to study differences between independent and paired samples respectively. The association between the studied parameters was assessed by means of the Pearson correlation coefficient. In all hypotheses, testing the observed significance level (p-value) was estimated using the Exact estimation method [28]. The aim of this method is to enable the researchers to make reliable infer- ences when the available data are small, sparse, heavily tied, or unbalanced and the validity of the usual assumptions (randomness of the sample and independence of observations) underlying the corresponding tests are not satisfied [29]. The significance level of all statistical hypothesis testing procedures was preset at 0.05 . All the statistical analyses were performed using the SPSS ver. 15.0 statistical package (SPSS Inc, Chicago, IL, USA) enhanced with the modules Exact Tests.

The site and not the patient has been the analysis unit. Therefore the study includes 30 sites per group and a total of 360 samples have been analysed. Many studies have looked at the association between total amount or concentration levels of different constituents of GCF and periodontal health status. Since host response is a critical determinant in periodontal disease pathogenesis, the measure of inflammatory mediator levels in the GCF has been used to evaluate 'risk': risk for a tooth, or more precisely a site, to lose clinical attachment and alveolar bone, or risk for an individual to develop periodontal disease [30].

\section{RESULTS}

\section{G.I., P.I., and G.C.F. Alterations}

All participants completed the four-week trial. The changes in the clinical signs of inflammation were obvious and the alterations in G.I., P.I. and GCF volume are presented in Table 1. The motivation and oral hygiene instruction of the participants undertaken during the pre -study period ensured that absence of plaque and bleeding were achieved at baseline in all test sites. In other words, at the start of the experimental period both groups had almost identical and comparatively low levels of gingivitis and plaque formation. Both the PI and GI increased in all patients between Days 0 and 21 and returned to baseline values by Day 28.The old group showed higher levels of bleeding and plaque scores at Day 21 (G.I. 1,966,P.I. 2,036) and Day 28 (G.I. 0,262, P.I. 0,162) which reached to be statistically significant at Day 21 and Day 28 for G.I., at Day 21 for P.I., (Table 1).

In all patients, a significant increase in GCF volume was induced by non-brushing compared with Day 0. Samples collected at Day 28 demonstrated a significant decrease compared with Day 21. Although a significant reduction in gingival crevicular fluid volume occurred after the reestablishment of oral hygiene, at Day 28 the GCF volume was still significantly elevated compared with the baseline for the old group.

\section{Cytokine Levels Changes}

All data concerning levels of TNF-a, IL-6, IL-8 during the whole study period are presented in Table 2 .

With respect to TNF-a, although at Day 0 the TNF-a levels were approximately the same $(4,69$ for the young group, 4,52 for the old), significant group differences were observed during the experimental gingivitis and recovery phase; mean 
concentration in the young group were lower than those of the old group at Day $21(3,84$ vs 7,56)and Day $28(5,4$ vs 9,5) (Fig. 1).
With respect to IL -6 the fluctuations between groups were opposite at each time point (Fig. 2). There was a decline at Day $21(3,91)$ and then an increase $(5,0)$ for the old adults and, contrariwise for the young group, there was an

Table 1. G.I., P.I., and G.C.F. Volume Alterations During the Study Period

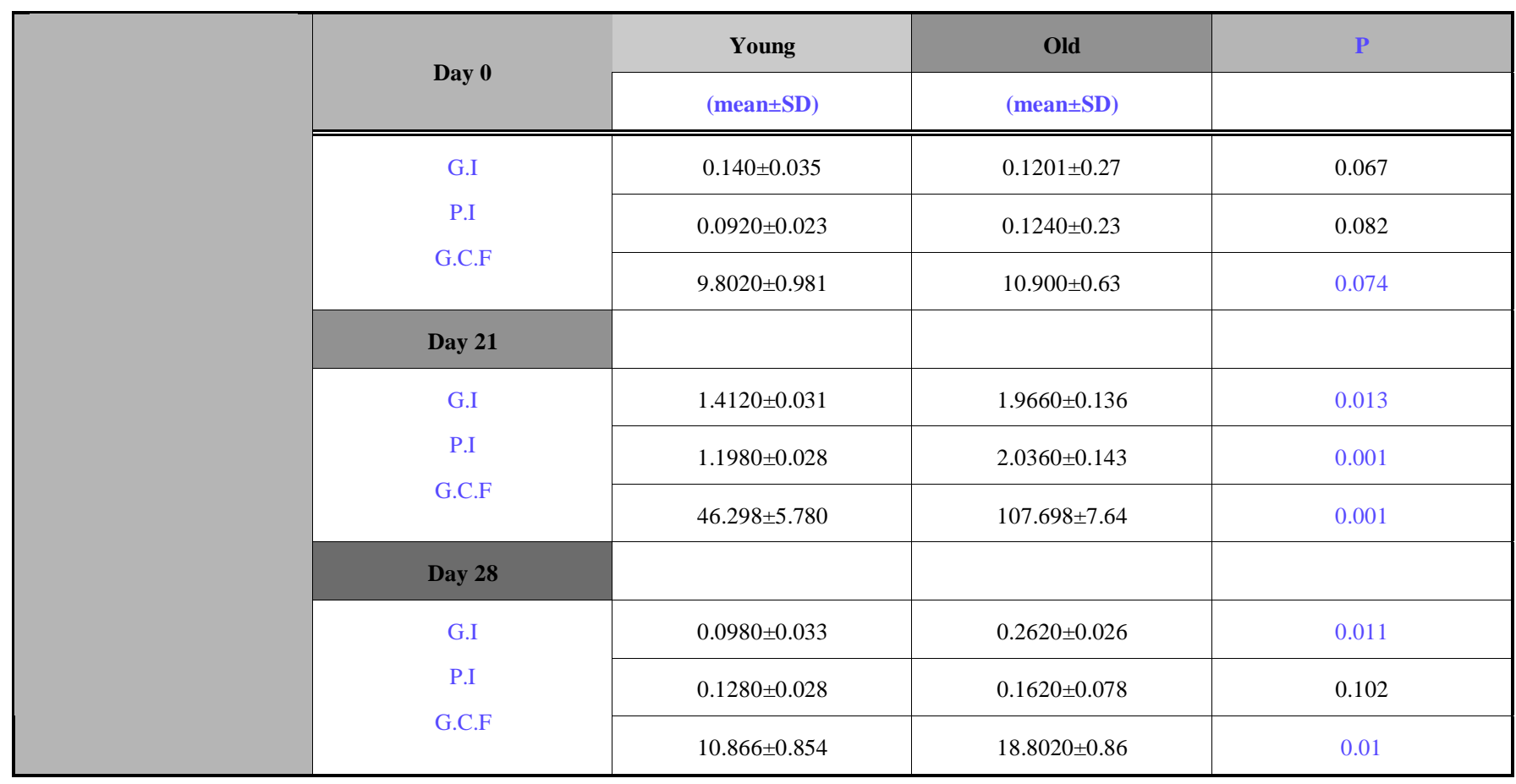

Table 2. Changes in Cytokine Levels During the Study Period (mean \pm SD)

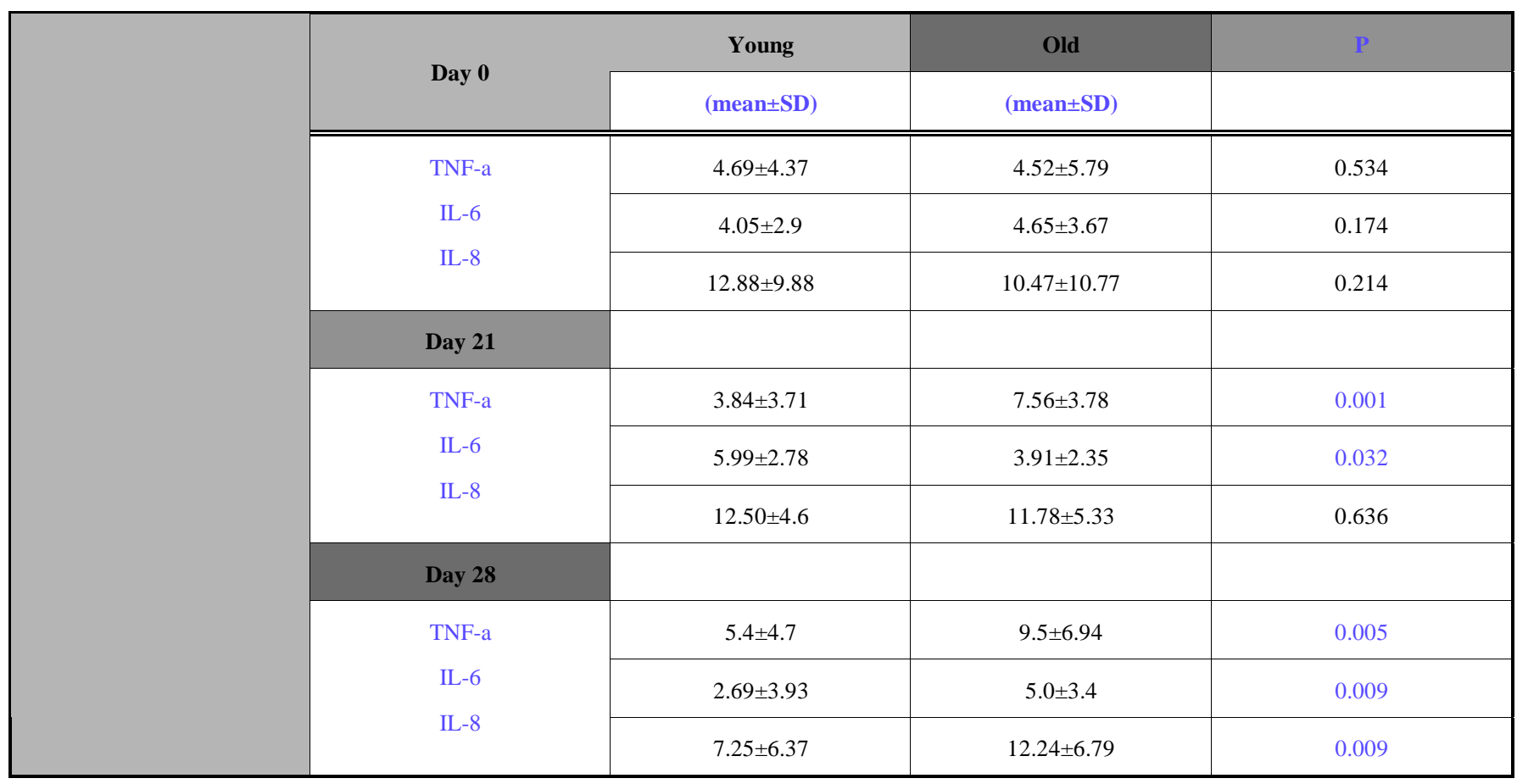




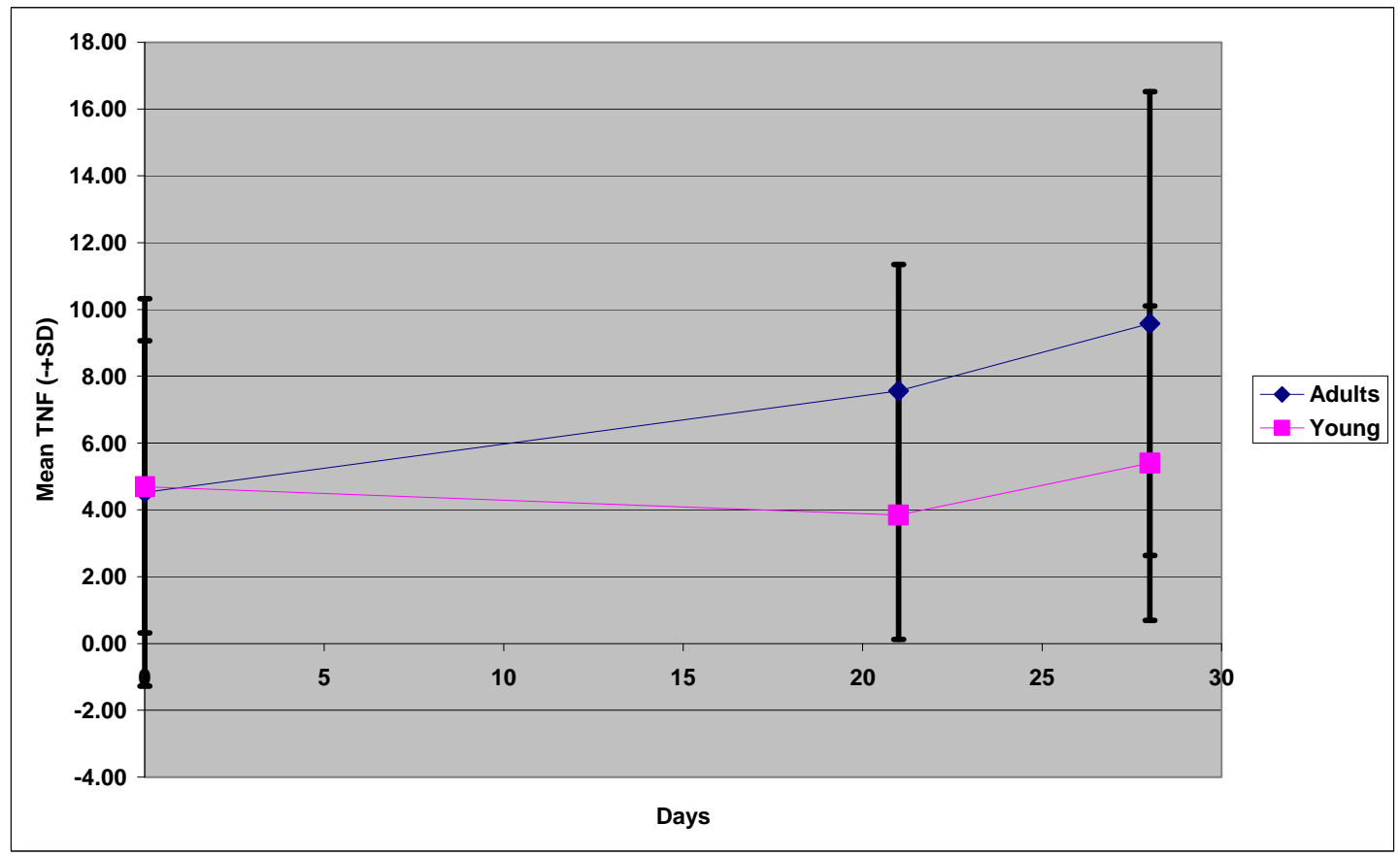

Fig. (1). TNF-a mean concentration in young and old group( adults) during the experimental gingivitis period.

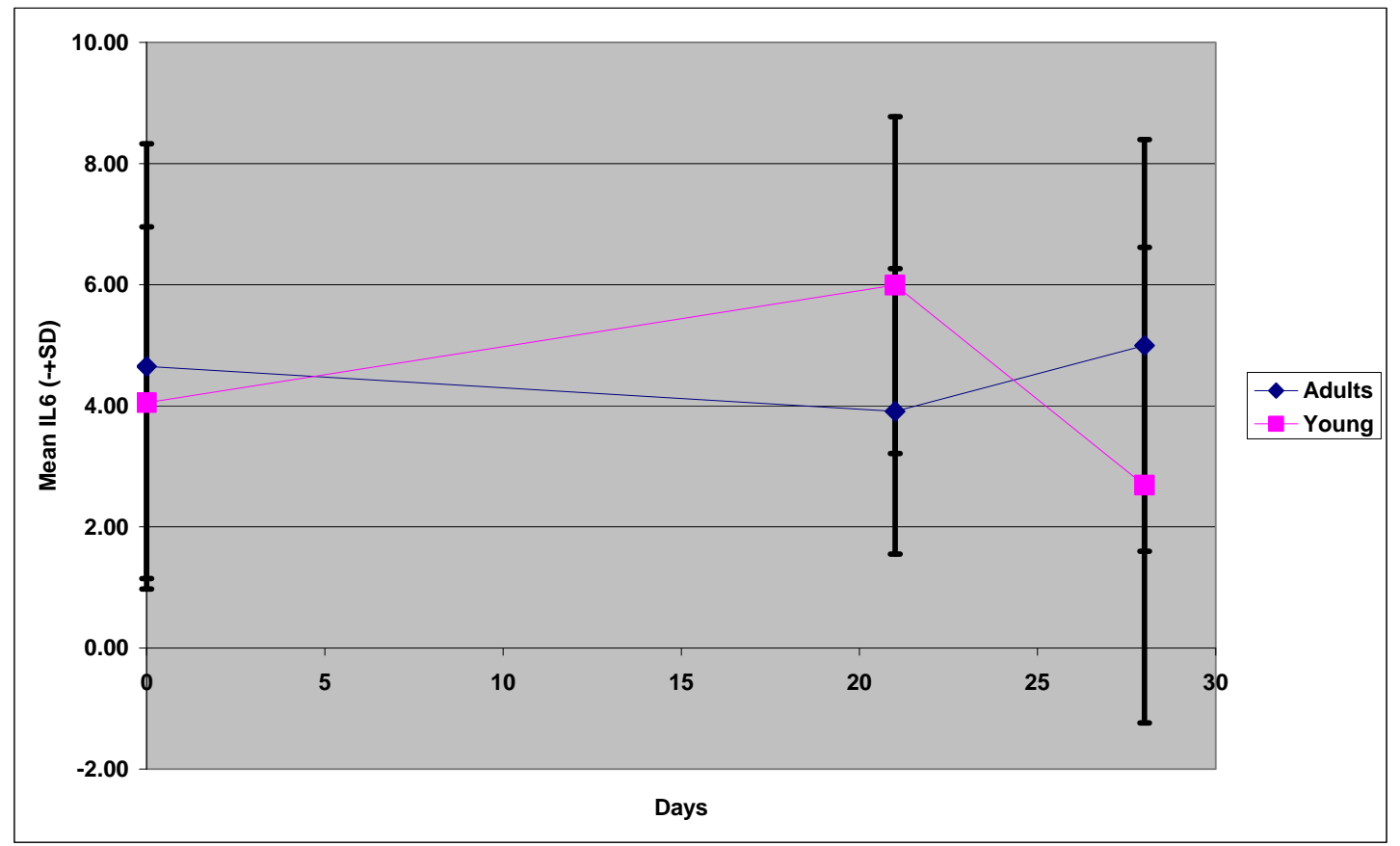

Fig. (2). IL-6 mean concentration in young and old group(adults) during the experimental gingivitis period.

increase at Day 21(5,99) and a decline at Day 28(2,69) and these differences both found to be statistically significant.

An interesting group difference was also observed for IL -8 (Fig. 3), where there was a steady increase for the old group during the whole 4 wk period $(10,47 \rightarrow 11,78 \rightarrow 12,24)$ and for the young group there was a slight increase from Day 0 to Day 21 (from 12,88 to 12,50 ) and a $40 \%$ decline from Day 21 to Day 28 (from 12,5 to 7,25). Mean concentrations in the old group were lower than that of the young group at Days 0 and 21, without being statistically significantly so, and higher at Day 28 which was found to be significant.

\section{Effects of Time on Clinical and Immune Parameters Within the Groups}

To assess whether parametrical means varied over time, repeated measures analysis of variance over the 4 wk study period were computed for the young and old groups respectively.

Within the young group, significant effects of time were observed for sites of bleeding, plaque scores and GCF volume at each time point. With respect to cytokine levels there were significant differences between Days 0 and 21 concern- 


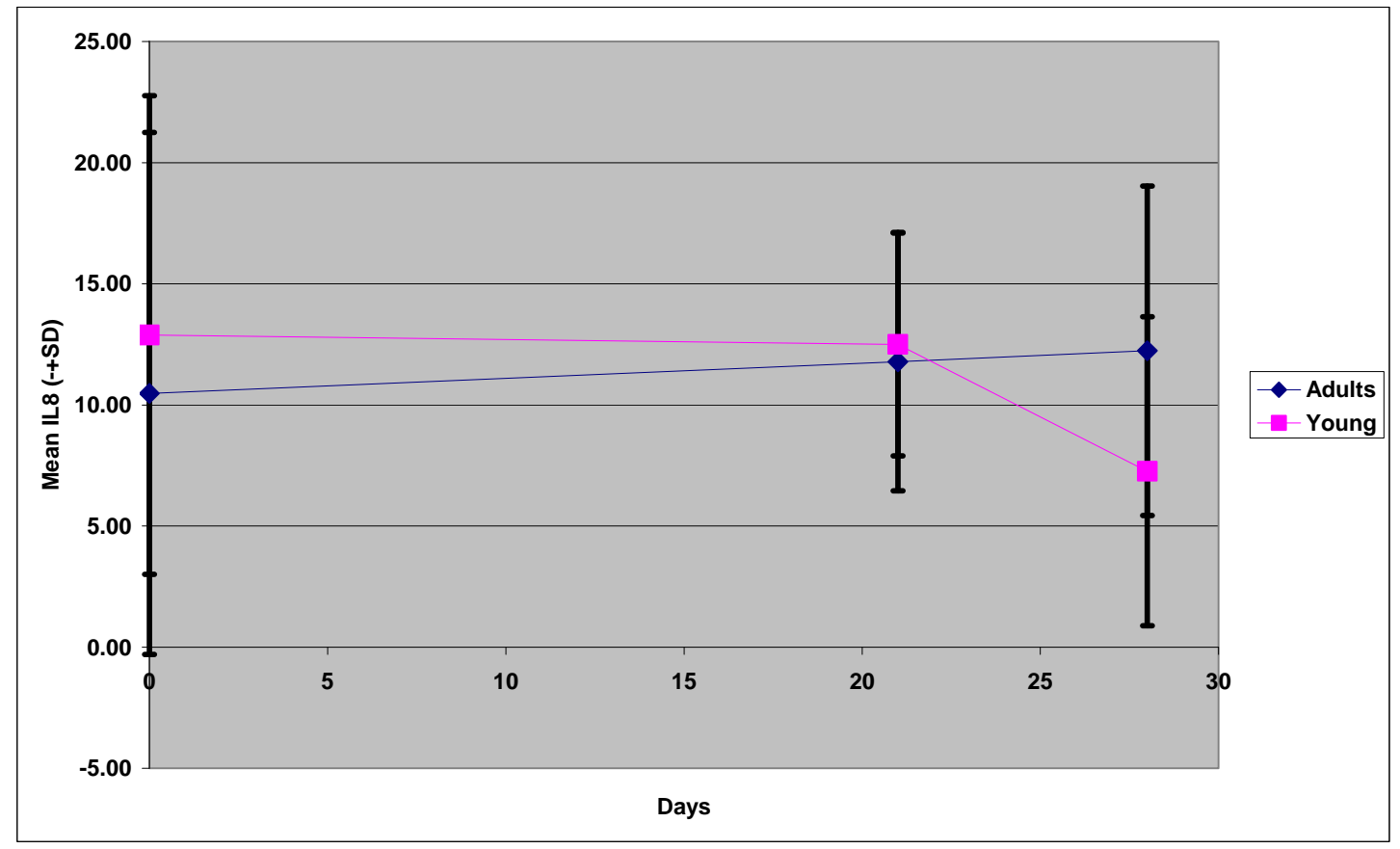

Fig. (3). IL-8 mean concentration in young and old group (adults) during the experimental gingivitis period.

ing only IL -6 , and between Day 21 and 28 concerning IL -6 and IL -8 .

No time effects were observed regarding young subjects for: TNF-a at each time point, IL -6 over the whole $4 \mathrm{wk}$ period, and for IL - 8 between Days 0 and 21(Figs. 1-3).

Within the old group, significant effects of time were observed for sites of bleeding, plaque scores, and GCF volume at each time point, for TNF-a between Days 0 and 21, and for IL -6 between Days 21 and 28 .

No time effects were observed regarding old subjects for IL -8 at each time point, for IL -6 during the whole 4 wk period and for TNF - a and IL - 6 between Days 0 and 21 (Figs. 1-3).

\section{Cytokine Correlations Within Groups}

The hypothesis that presence of one cytokine may influence the levels of the others was also investigated and the results are presented in Figs. (4-11). In all cases, the best fitting curve (red dotted line) was plotted by means of the Loess method [31] for $90 \%$ of points to fit.

At Day 0 a moderately strong correlation was observed between IL -8 and IL -6 for the old group $(r=0.359$, $\mathrm{p}=0.05)($ Fig. 4) and a strong one concerning the young group $(\mathrm{r}=0.580, \mathrm{p}=0.001)$ (Fig. 5). At Day 21 a strong correlation between TNF-a, and IL-6 ( $\mathrm{r}=0.489, \mathrm{p}=0.006)$ (Fig. 6) and a moderate corellation between TNF-a and IL-8 $(r=0.359$, $\mathrm{p}=0.05$ ) was observed for the young group (Fig. 8), and a strong correlation between IL-6, and IL-8 (Fig. 7) ( $r=0.803$, $\mathrm{p}<0.001$ ) concerning the old group (figure). After recovery at Day 28 TNF-a and IL-6 ( $\mathrm{r}=0.713, \mathrm{p}<0.001)$ showed a strong correlation (Fig. 9) as did TNF-a and IL-8 (Fig. 10) (r=0.649, $\mathrm{p}<0.001)$ for the old group. However the young group showed for TNF-a and IL-8 a negative moderate to strong correlation $(\mathrm{r}=0.439, \mathrm{p}=0.015)$ (Fig. 11).

\section{DISCUSSION}

The present study compared the clinical parameters and the levels of IL-6, IL -8 and TNF-a in gingival crevicular fluid during 4weeks of experimental gingivitis between young and old subjects. The results indicate that there are differences between the inflammatory responses in young and adult individuals during the course of experimental gingivitis, with old volunteers developing more gingivitis than the younger ones. This was documented by both clinical measurements and GCF volume determinations. The more pronounced deposition of microbial plaque in the old group, especially at the end of study period, could be attributed to the occurence of recession or abrasions, that favor the deposition of microbial plaque [32]. These findings corroborate clinical data previously reported by Holm-Pedersen et al. (1975), and Fransson et al. (1996) [33, 34] in human trials and Berglundh and Lindhe (1993) [35] from an animal model. They reported that the normal gingiva of groups of young adults had many features in common with those of old group of adults, but that gingival lesions resulting from abolishing oral hygiene for three weeks were significantly larger in subjects from the old group. On the other hand, Winkel et al. (1987) [36] presented data indicating an absence of differences in inflammatory response between the two study groups. Nevertheless, the age variation in the latter experiment was only 20 years [36], relatively low when compared to the previously mentioned studies $[33,34]$ and also ours (40 years).

The results of the present study confirm previous findings $[3,37,38]$ and clearly demonstrate that when oral hygiene procedures are interrupted, an increase in plaque accumulation and the establishment of clinically relevant mucosal inflammation occurs. A relationship between GCF and gingival inflammation has been reported previously [39, 40]. 


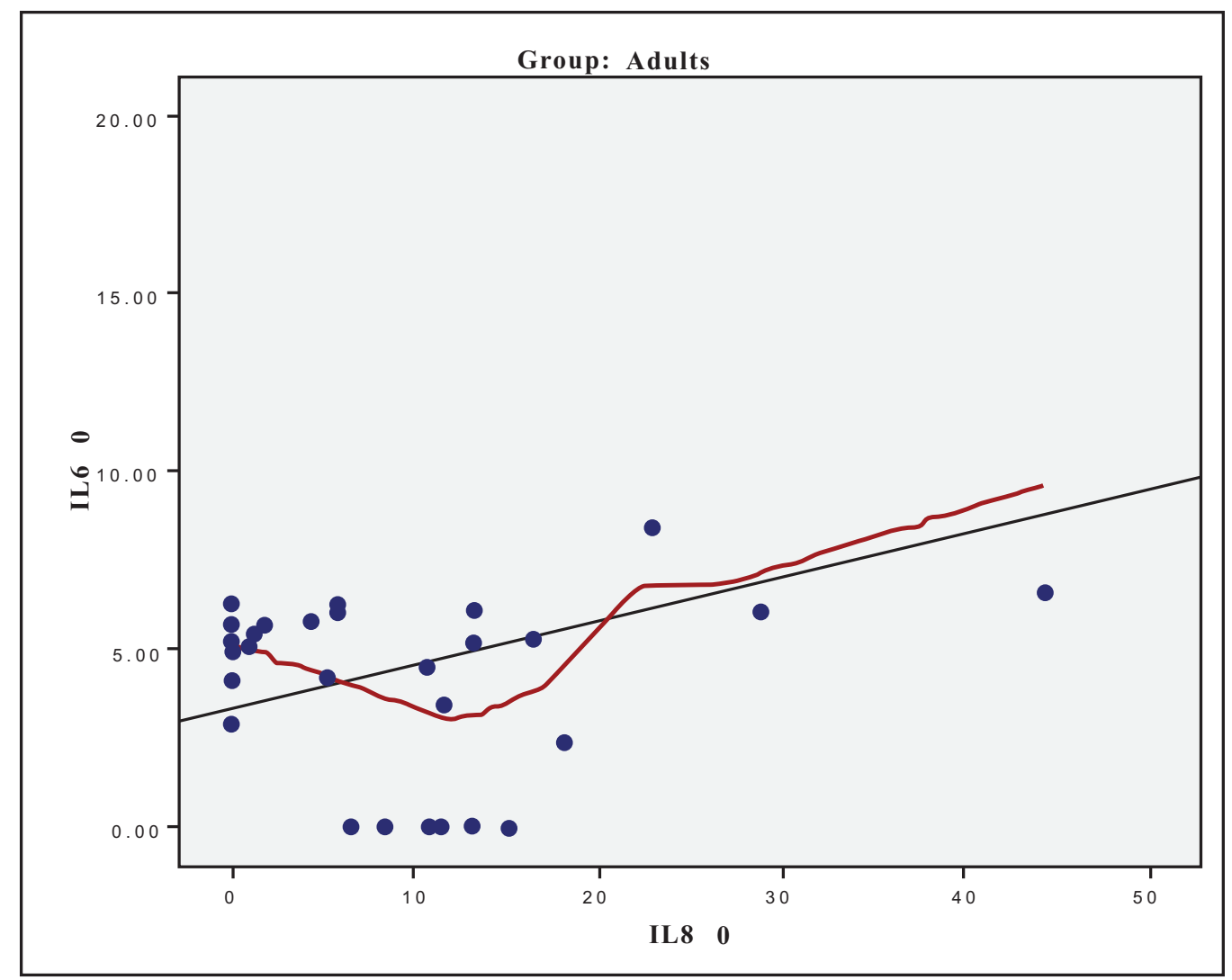

Fig. (4). Scatter plot presenting the correlation between IL-8 and IL-6 at day 0 for the old group (adults).

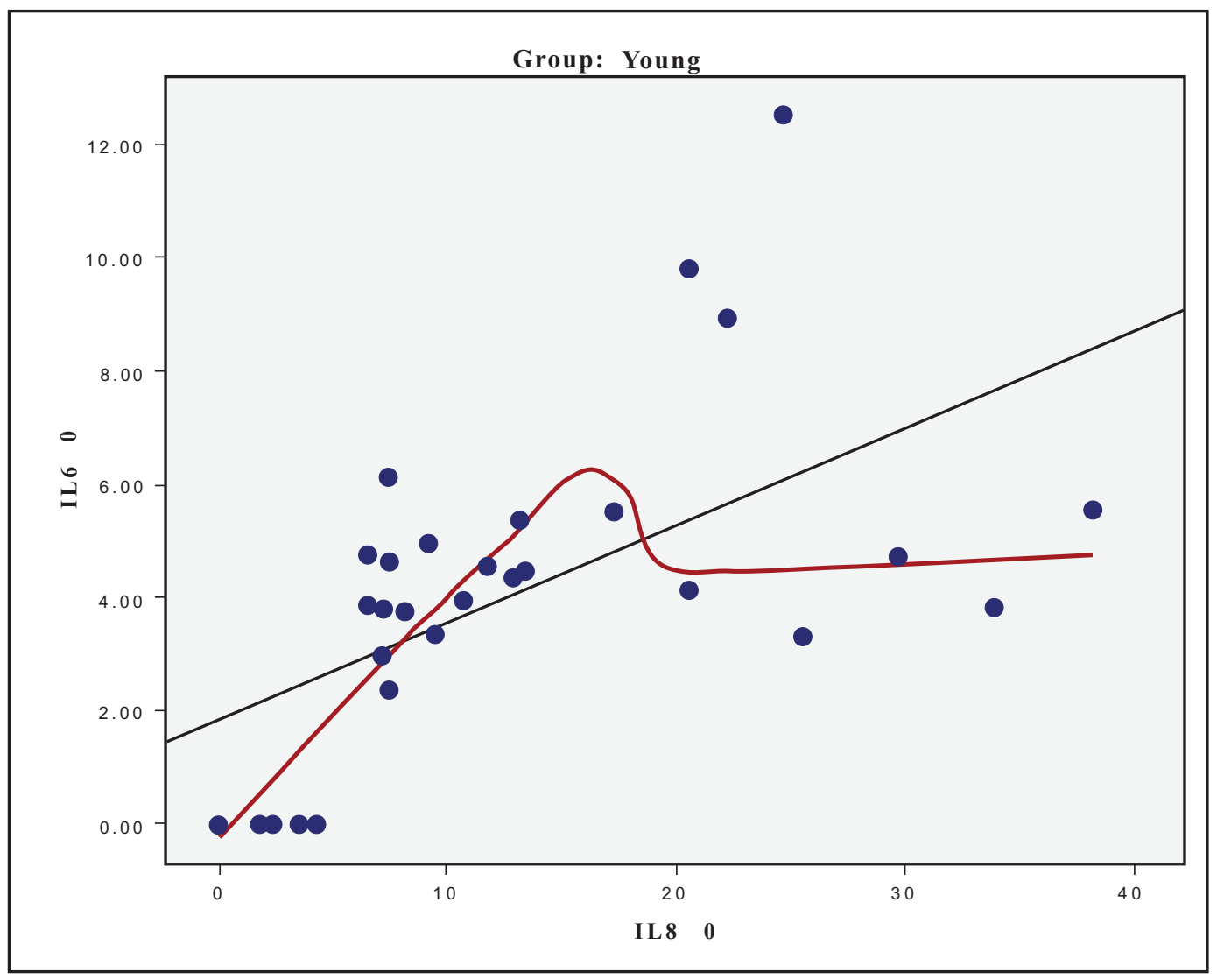

Fig. (5). Scatter plot presenting the correlation between IL-8 and IL-6 at day 0 for the young group. 


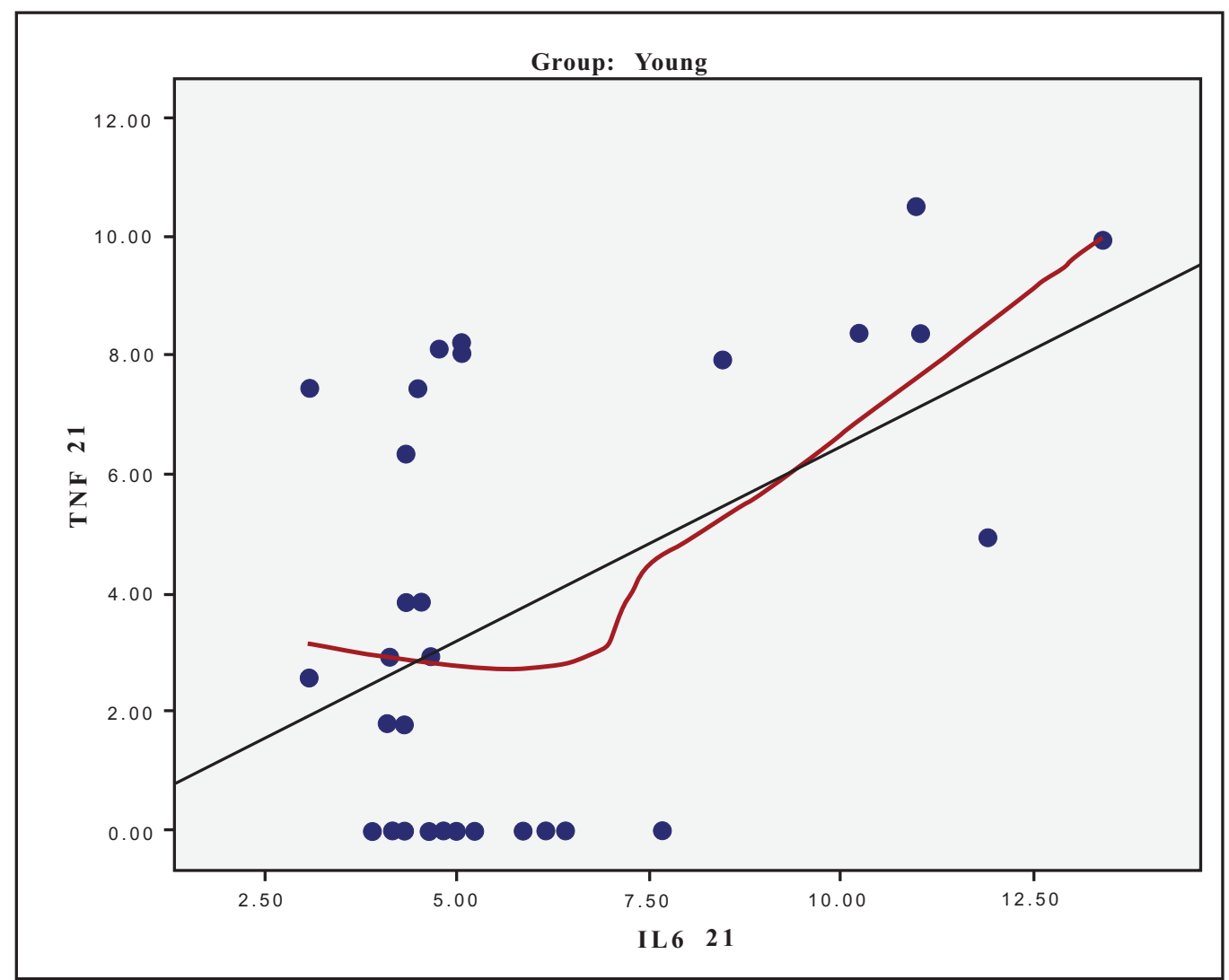

Fig. (6). Scatter plot presenting the correlation between IL-6 and TNF-a at day 21 for the young group.

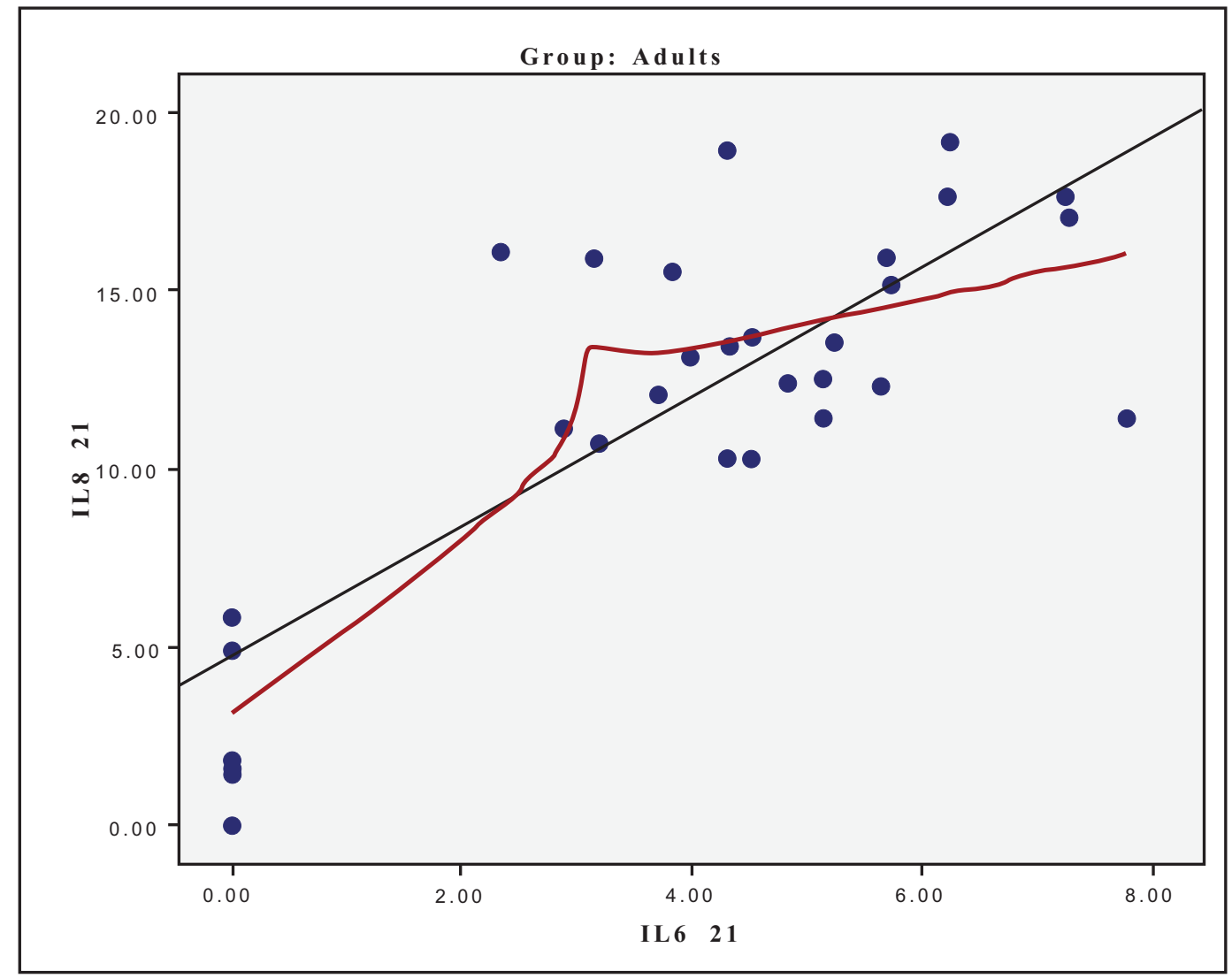

Fig. (7). Scatter plot presenting the correlation between IL-6 and IL-8 at day 21 for the old group(adults). 


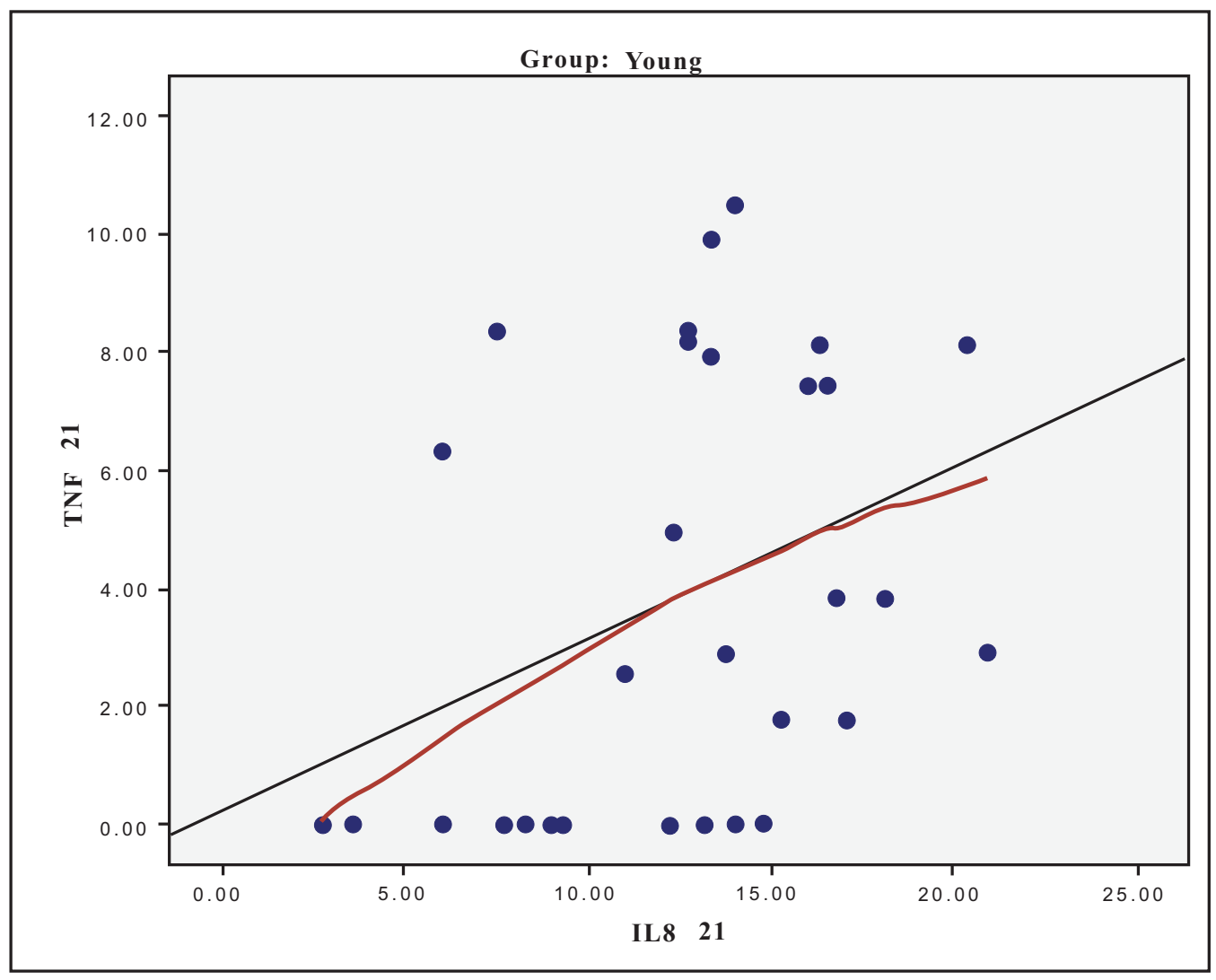

Fig. (8). Scatter plot presenting the correlation between IL-8 and TNF-a at day 21 for the young group.

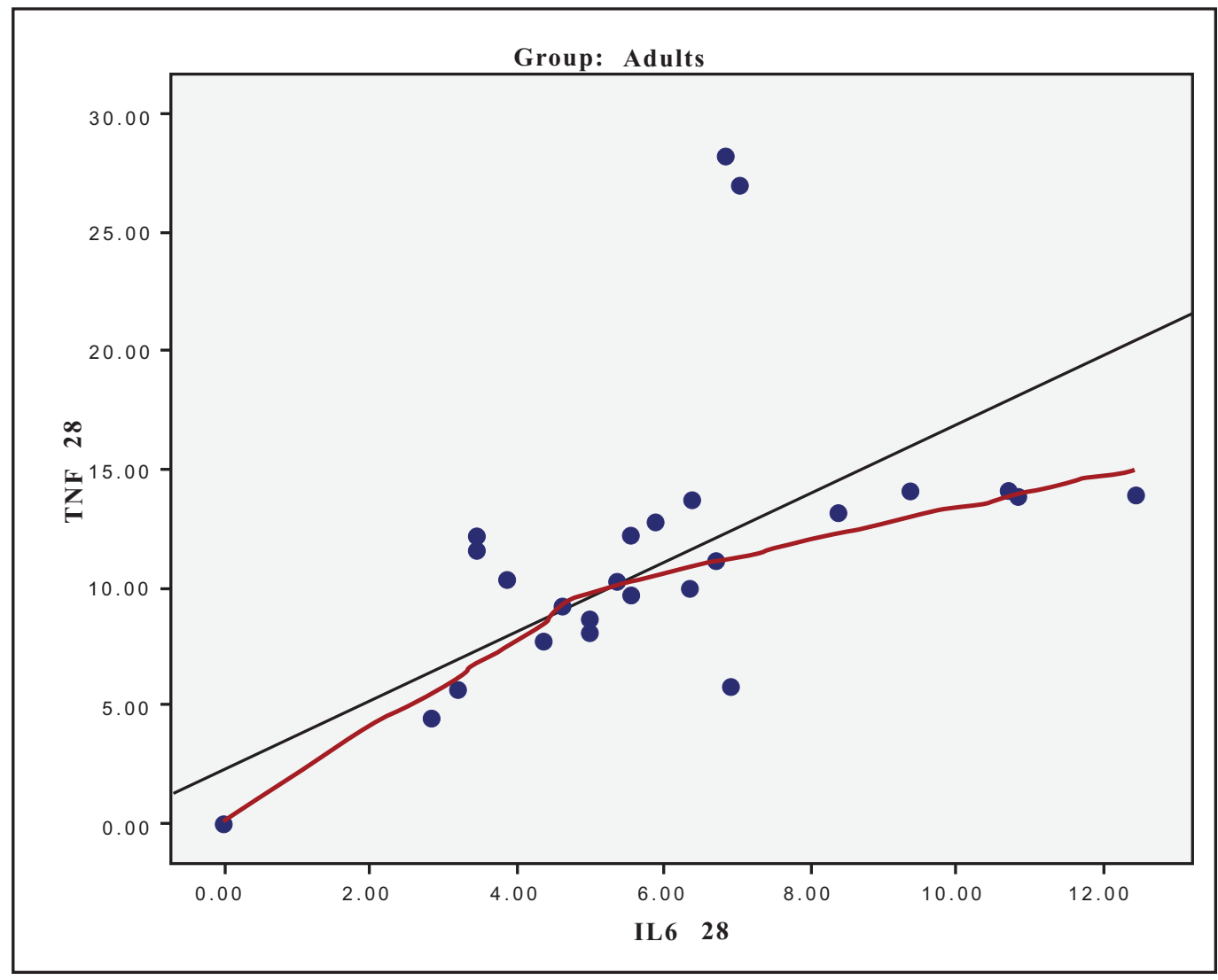

Fig. (9). Scatter plot presenting the correlation between IL-6 and TNF-a at day 28 for the old group (adults). 


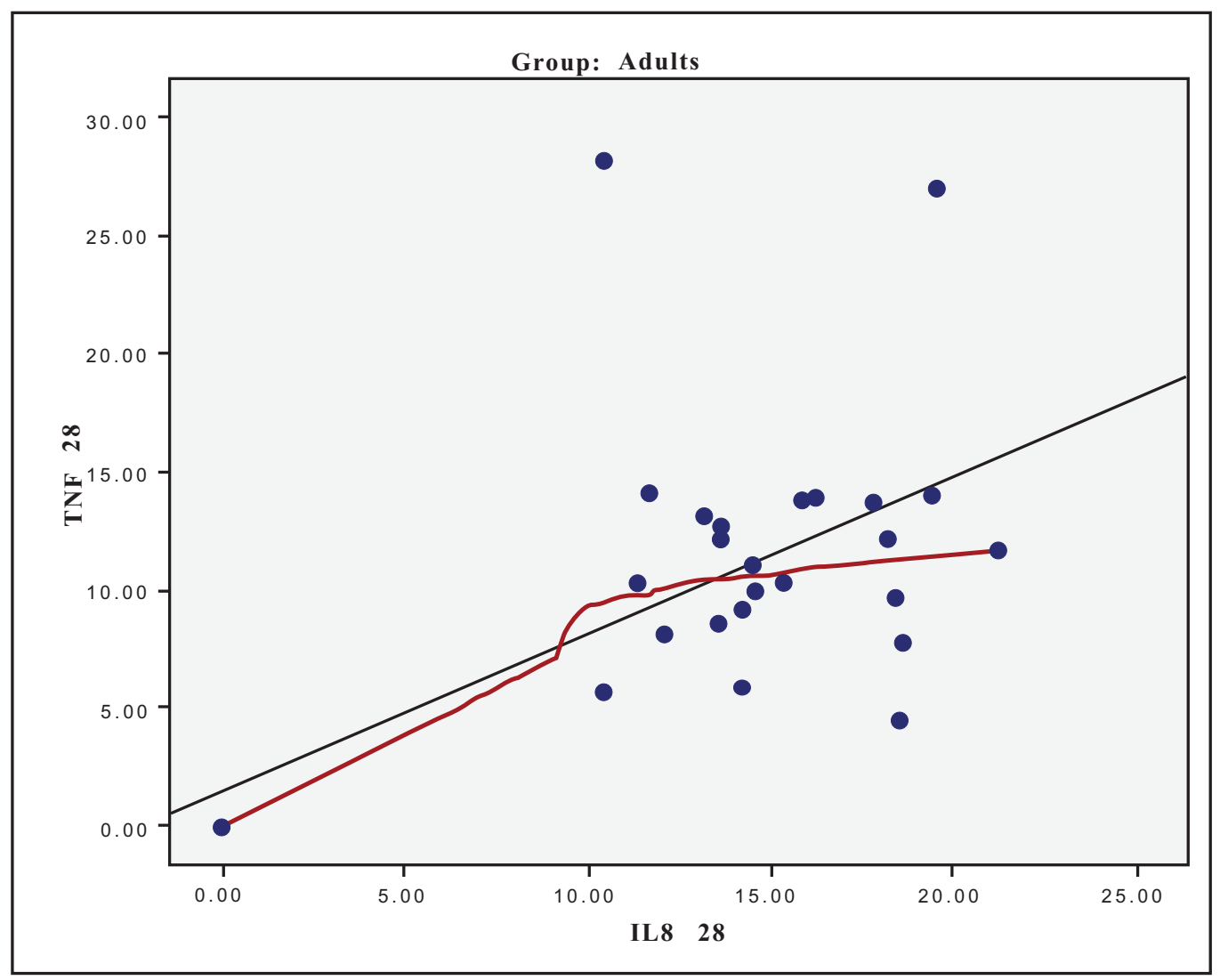

Fig. (10). Scatter plot presenting the correlation between IL-8 and TNF-a at day 28 for the old group (adults).

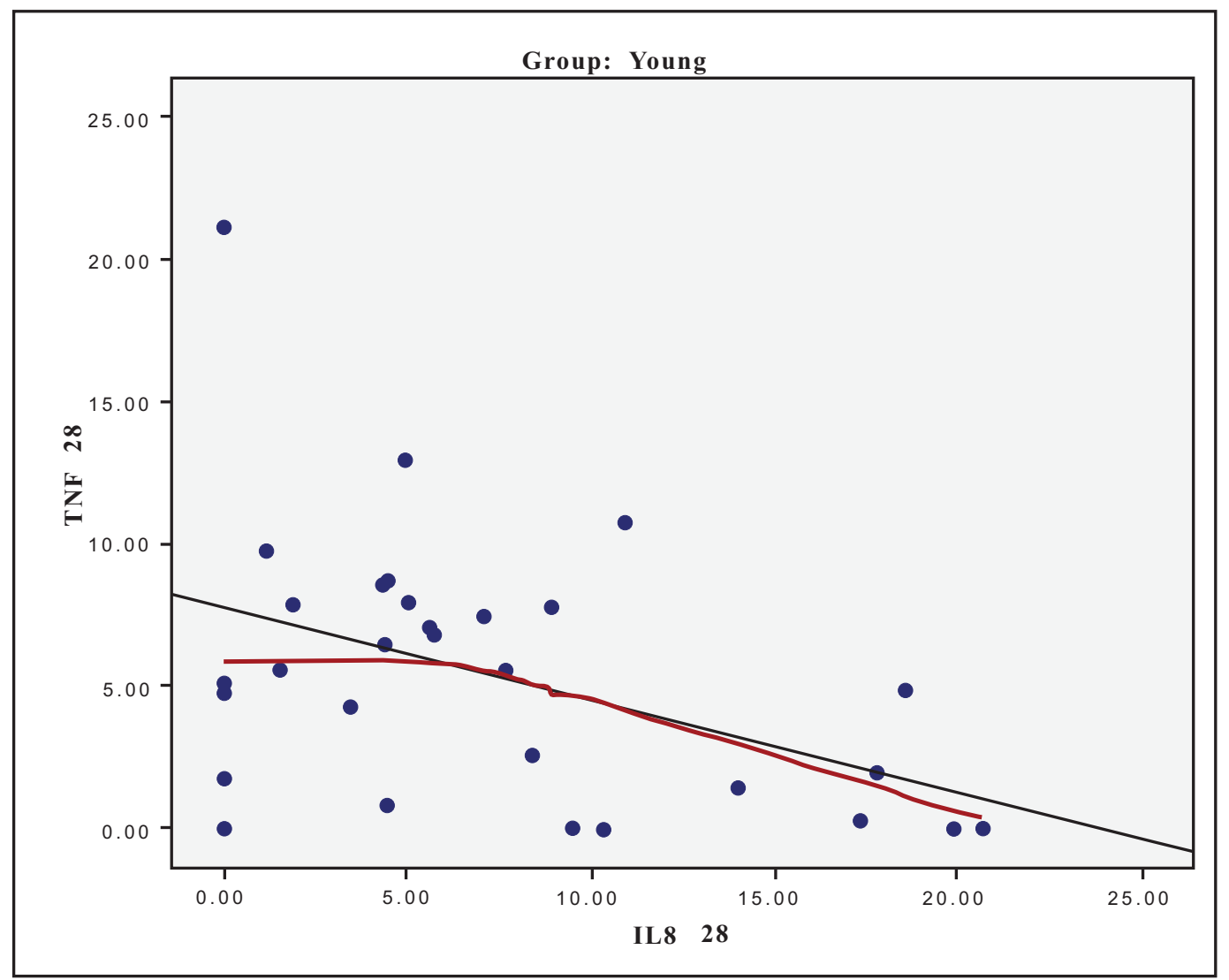

Fig. (11). Scatter plot presenting the correlation between IL-8 and TNF-a at day 28 for the young group. 
In this study, all patients showed a significant increase in GCF volume after 21 days of no oral hygiene. After oral care was resumed, this volume decreased significantly. Although a significant reduction in volume occurred after the reestablishment of oral hygiene, at day 28 , the GCF volume was still significantly elevated compared with the baseline for the old group.

As expected from results of earlier studies, considerable fluctuations with respect to cytokines level were observed during the experimental gingivitis process in this research. Most of the subjects exhibited measurable TNFa levels and the mean concentrations at baseline were approximately the same for the two groups.

No significant changes in the overall amount of cytokines was evident between healthy, pathological and recovery (Day 0, Day 21 and Day 28 respectively) values for the young group. This finding replicates findings of previous studies [41]. On the other hand, the old group showed a steady increase during the $4 \mathrm{wk}$ period in TNF-a levels, which is hard to explain in terms of previous findings since there have not been other studies investigating the effect of age on TNF-a values during an experimental clinical trial. The authors previously investigated the levels of IL-1a, IL$1 \mathrm{~b}$ in young and old adults using the experimental gingivitis model [9] It was found that old adults had higher levels of IL-1b.

IL-8 seemed to stabilize after slightly increased concentrations at the first measurement for the old group, while, on the contrary, the young group showed a marked decrease from Day 21 to Day 28. In the Zhang et al. (2002) [42] study, which analyzed the experimental gingivitis effects on crevicular IL-8 concentrations, a $60 \%$ decline of IL -8 was found from Day 0 to Day 3. Probably plaque, per se, may induce an IL-8 reduction. A more recent study [1] compared cytokine concentrations (IL-1b, IL-8) between experimental and persistent gingivitis conditions. The experimental gingivitis subjects showed lower IL-8 concentrations than subjects with persistent gingivitis. It must be noted that the sample of this study was drawn from University students and therefore strongly resembles the characteristics of the young group in the present study. In an vitro study in human gingival fibroblasts, less IL-8 was produced when cultured together with capsula polysaccharide of Aggecatibacter actinomycetemcomitans [43]. Finally, a reduction in IL-8 has caused recent speculation about its importance as a pathogenic factor in chronic inflammatory diseases such as helicobacter-associated duodenal ulcer [44] and Crohn's disease [45].

With respect to IL-6 the old group showed a decrease at Day 21 compared to baseline but the changes during the whole 4 wk period failed to be statistically significant. On the other hand the young group presented a markedly decrease in IL-6 mean concentrations at Day 28 compared to Days 0 and 21.

Gingivitis and the other periodontal diseases are viewed today as multifactorial pathogenic entities that are initiated and sustained by bacteria but significantly modified by the host's response to bacterial plaque. The factors that were controlled or measured and analyzed were: gender, smoking status, age and chronic gingivitis level. The results add support to the hypothesis that male subjects show less variation, however there is limited evidence linking the female menstrual cycles to variations in gingivitis status. Further research in this area is required before definitive conclusions can be made. However, although there is sufficient evidence to justify balancing for (or excluding) smokers from subject populations in experimental gingivitis studies, this could not be documented for the age factor [46].

Age related changes in proliferative activity in human gingival epithelium remain unclear. Nuclear proliferating cell nuclear antigen (PCNA) immunoreactivity is found in the proliferative compartment of normal gingiva. Celenligil Nazlien et al. (2000) [47] investigated the localization of PCNA, which is a nuclear protein associated with the cell cycle in oral gingival epithelium and defined the age-related changes as to the PCNA-proliferative index (PI) in inflamed as well as healthy gingiva. Additionally, the mitotic index (MI) was used as a conventional marker of cell proliferation, and the effect of aging upon the maximum epithelial thickness (MET) was determined. Biopsies were obtained both from healthy and inflamed gingiva from old and middle aged subjects. They concluded that PCNA expression in inflamed gingiva was higher in old subjects. Furthermore, a significant correlation was noted between aging and PCNA expression in inflamed gingiva. As no increase in mucosal epithelial thickness was determined despite increased proliferation, it was speculated that the duration of the PCNA+ phase in cell cycle might be longer in old subjects. PI in inflamed gingiva was significantly higher in the old group. However, no significant difference was observed between the study and control groups with respect to PI in healthy gingiva. When all the subjects taking part in the study were analyzed as a single group, PI in the inflamed gingival samples was found to increase with aging. Nevertheless, no age-related change was noted in MI and MET. In both groups, PI, MI, and MET were found to increase due to inflammation. Siegel et al. [48] investigated the expression of cyclooxygenase-1, cyclooxygenase- 2 , cyclooxygenase- 3 , and microsomal prostaglandin E synthase-1 in young and elderly subjects. They concluded that Cyclooxygenase-1 and microsomal prostaglandin E synthase-1 were expressed constitutionally in gingival tissue, and expression was unaffected by age or inflammation states. In contrast, the expression of cyclooxygenase- 2 was weaker in elderly subjects. In the course of experimental gingivitis, cyclooxygenase- 2 was induced in both age groups.

It is feasible that a concept such as the "susceptibility profile", described for other diseases [49], may also pertain to both gingivitis and periodontitis, where several relatively common high-risk polymorphisms could be inherited by an individual, giving him a cumulative high-susceptibility profile. Tatakis et al. 2004 [50] identified two subpopulations characterized by significant differences in clinical parameters of plaque-induced gingival inflammation, despite similar amounts of plaque deposits and plaque accumulation rates. Studies on the possible genetic/age factors determining or modulating susceptibility to gingivitis are limited [51-54]. It has been shown that children with Down's syndrome manifest more extensive and severe gingival inflammation at an 
earlier age than age- and gender-matched healthy controls, despite having no differences in plaque accumulation rates [52]. This study represents the only definitive report of a genetic condition associated with susceptibility to plaqueinduced gingivitis. Recently [55] (Scapoli et al. 2005) have demonstrated an association between IL-1RN polymorphism and subject-based clinical behaviour of the gingiva in response to de novo plaque accumulation, (as well as a possible association between IL- $1 \beta^{-511}$ polymorphism and gingivitis susceptibility). In contrast, the results emerging from other studies on IL-1 polymorphisms in different ethnic groups $[51,54]$ and from a study on polymorphisms in TNFa, LT-A and IL-6 genes [56] seem to indicate that, if there is a role for any of these variants in the inflammatory process involved in gingivitis, it will be either population specific and/or may exert a minor effect on the clinical expression of plaque-induced gingivitis.

In both population studies and controlled clinical trials, some variables, such as smoking, body mass index, and hormone replacement therapy have been shown to influence concentrations of inflammatory mediators, but it remains unclear why some persons have consistently elevated systemic inflammatory responses [57]. It seems reasonable, therefore, to determine whether genetic differences contribute to the variance in inflammatory mediator expression and whether that genetic effect influences an individual's risk of chronic diseases. This information could then be used to develop approaches to reduce the morbidity of diseases of aging [58].

Social smokers (no more than five cigarettes per day) were included in this study considering that social smoking is often identified with occasional and not everyday use and especially more often in social settings. This is in accordance with studies [59] considering that consuming less than 10 cigarettes per day is not a high risk factor for periodontitis development. Also the definition of smokers appears unclear in different studies $[60,61]$. Nevertheless, it is always important to keep in mind that the self reported history may not be a reliable method to assess smoking exposure; probably biochemical tests to measure serum levels of metabolites of nicotine should be used instead [62].

A remarkable finding from the present study is that the variations in clinical and GCF volume parameters differed between young and old subjects, suggesting that the periodontal tissues between groups responded differently to de novo plaque formation. Is therefore age a factor in differing susceptibility to experimental gingivitis or even more to chronic gingivitis?

Brecx et al. (1987) [63] performed an experimental gingivitis study in 8 dental students (a group identical to our young adults) and reported that plasma cells occupied only $1 \%$ of the lesions. Differences in the cellular composition of the gingival lesions were also detected by Page et al. (1975) [64] in a study in young and old monkeys, and by [35] Berglundh and Lindhe (1993) who investigated developing gingivitis in young and old dogs. These observations were also confirmed by Fransson et al. (1996) [65], who indicated that the composition of the gingival lesion at Day 21 was markedly different in young and old humans.
However, it is important to keep in mind that experimental gingivitis, an extensively studied model of gingivitis, is similar but not identical to chronic gingivitis in more natural settings. This was confirmed in the study of Deinzer et al. (2007), [1] which compared cytokine concentrations (IL$1 \mathrm{~b}, \mathrm{IL}-8)$ between experimental and persistent gingivitis conditions. The results of this study showed that subjects with different conditions (i.e. experimental and persistent gingivitis) were not comparable with respect to clinical parameters, IL-1 and IL-8. Although both conditions reflect the host's response to plaque bacteria, they differ in certain important aspects The authors raised the logical question as to what degree is the experimental gingivitis model comparable to more natural conditions where periodontal tissues are under the influence of persistent plaque, and if the immune response observed after 21 days of plaque accumulation is similar to that observed in persistent gingivitis.

In terms of our study, whereas clinical indices and GCF volume variations exhibit a distinct difference between the two groups (young and old subjects) that was not the case for the cytokine profile in GCF. As concerning the limits of the present study, it is important to notice that cytokines were not detectable in all sites and therefore the data presented on the scattered plots exhibited a wide range of deviation.

IL-8 is a pro-inflammatory chemokine produced by various types of cells upon stimulation, and is considered the most important mediator for the recruitment and activation of neutrophils [19, 20]. Plaque accumulation can possibly lead to an increase in the concentration and total amounts of IL- 8 in GCF. In the present study, IL- 8 levels in old subjects increased over the whole experimental period, an increase that was statistical significant between Days 0 and 21, but not between Days 21 and 28. In contrary, young adult subjects showed a decrease between Day 0 and 21 which reached a statistically significant level at Day 28 when compared with both Days 0 and 21. Conflicting results on the association of IL-8 and the degree of inflammation have been also reported previously. On the one hand, an inverse relationship between IL- 8 and PMN recruitment has been observed [66, 67], as well as lower GCF levels of IL- 8 in localized periodontitis as compared to healthy subjects [68]. On the other hand several other studies have suggested a positive relationship between GCF IL- 8 activity and periodontal disease [22, 23, 69]. Based on the above, the results from our study cannot be used to demonstrate a distinct difference in the way that IL- 8 levels vary between young and old subjects.

TNF-a and IL- 6 have a central role in the immunopathology of periodontal disease. They are both produced by the same variety of cells, with macrophages likely to be the most important source of these mediators in the early stages of gingival inflammation [70, 71], while TNF- a acts synergistically with IL-1b to stimulate gingival fibroblasts to enhance IL-6 secretion [72]. Also, in clinical healthy gingival tissues IL- 6 and TNF-a are present at a low level. This means that cytokines are also prominent actors in normal tissue homeostasis [73]. In the present study, both cytokines were detectable for both groups at baseline, but there was no statistically significant difference in their levels, which could 
be attributed to the difference in age between the groups. During the gingivitis period (Day 0 to 21), TNF- a showed a statistically significant increase in the old subjects, while in the young subjects it did not reach a statistically significant difference. The opposite pattern was seen for IL- 6, which showed a statistically significant increase only in young adult subjects. Interestingly, TNF- a levels continued to increase after professional cleaning and the re-establishment of oral hygiene procedures. This finding demonstrates that one week is probably not an adequate observation period for alterations in cytokine profile. The fact that in our study fluctuations in the levels of IL- 6 did not change similarly to those of TNF- a, can be explained by the variety of different ways that IL-6 release is triggered from different kinds of cells [74].

The results of this study showed that there are variations in the clinical parameters and gingival crevicular fluid volume levels between the young and old populations. However, it can be concluded that, within the limitations of the present study, age cannot be identified as a factor that strongly affects the cytokine expression and fluctuations, even in a well-controlled environment of inflammation, such as experimental gingivitis.

\section{REFERENCES}

[1] Deinzer R, Weik U, Kolb-Bachofen V, Herforth A. Comparison of experimental gingivitis with persistent gingivitis: differences in clinical and cytokine concentrations. J Periodont Res 2007; 42: 318-24.

[2] Van Dyke TE, Serhan CN. Resolution of inflammation: a new paradigm for the pathogenesis of periodontal diseases. J Dent Res 2003; 82(2): 82-90.

[3] Loe H, Theilade E, Jensen SB. Experimental gingivitis in man. J Periodontol 1965; 36: 5-15.

[4] Genco RJ. Host responses in periodontal diseases: current concepts. J Periodontol. 1992; 63: 338-55.

[5] Deinzer R, Forster P, Fuck L, Herforth A, Stiller-Winkel R, Idel H. Increase of crevicular interleukin 1 beta under academic stress at experimental gingivitis sites and at sites of perfect oral hygiene. $\mathbf{J}$ Clin Periodontol 1999; 26: 1-8.

[6] Birkedal-Hansen H. Role of cytokines and inflammatory mediatorsin tissue destruction. J Periodontol Res1993; 28: 500-10.

[7] Preiss DS, Meyle J. Interleukin-1 beta concentration of gingival crevicular fluid. J Periodontol 1994; 65: 423-8.

[8] Kinane DF, Winstanley FP, Adonogianaki E, Moughal NA. Bioassay of interleukin 1 (IL-1) in human gingival crevicular fluid during experimental gingivitis. Arch Oral Biol 1992; 37(2): 153-6.

[9] Tsalikis L, Parapanisiou E, Bata-Kyrkouy A, Polymenides Z, Konstantinidis A. Crevicular fluid levels of interleukin-1alpha and interleukin 1-beta during experimental gingivitis in young and old adults. J Int Acad Periodontol 2002 ; 4: 5-11.

[10] Masada MP, Persson R, Kenny JS, Lee SW, Page RC, Allisson MC. Measurement of intreleukin $-1 \mathrm{a}$ and $-1 \mathrm{~b}$ in gingival crevicular fluid: implications for the pathogenesisof periodontal disease. J Periodontal Res 1990; 25: 156-63.

[11] Reinhardt RA, Masada MP, Johnson GK, Dubois LM, Seymour GJ, Allisson AC. IL-1 in gingival crevicular fluid following closed root planing and papillary flap debridement. J Clin Periodontol 1993; 20: 514-19.

[12] Beutler B, Grau GE. Tumor necrosis factor in the pathogenesis of infectious diseases. Crit Care Med 1993; 21: 423-35.

[13] Holmes CL, Russell JA, Walley KR. Genetic polymorphisms in sepsis and septic shock: role in prognosis and potential for therapy. Chest 2003; 124: 1103-15.

[14] Murray J, Barbara J, Dankley S, et al. Regulation of neutrophil apoptosis by tumor necrosis factor-A. requirements for TNF-R55 and TNF-R75 for induction of apoptosis in vivo. Blood 1997; 90 (7): $2772-83$.

[15] Tracey K, Cerami A. Metabolic response to cachectin/TNF. annals of the New York academy of sciences. In: Bolland B, Cullinan J, Kimballi C, Eds. New York: Academy of Sciences 1990; vol. 587: pp. 325-30.

[16] Ridker PM, Brown NJ, Vaughan DE, Harrison DG, Mehta JL. Established and emerging plasma biomarkers in the prediction of first atherothrombotic events. Circulation 2004; 109(25 Suppl 1): IV6-19.

[17] Wiebe SH, Hafezi M, Sandhn HS, Sims SM, Dixon SJ. Osteoclast activation in inflammatory periodontal diseases. Oral Dis 1996; 2 : 167-80.

[18] Yamamoto M, Fujihashi K, McGhee JR, Vandyke TE, Kiyono H. Molecular and cellular mechanisms for periodontal diseases: role of cytokines in induction of mucosal inflammation. J Periodontal Res 1997; 32: 115-9.

[19] Bickel M. The role of IL-8 in inflammation and mechanisms of regulation. J Periodontol 1993; 64: 456-60.

[20] Baggiolini M. Chemokines and leukocyte traffic. Nature 1998; 392: 564-8.

[21] Tsai CC, Ho YP, Chen CC. Levels of interleukin-1b and interleukin-8 in gingival crevicular fluids in adult periodontitis. J Periodontol 1995; 66: 852-9.

[22] Mathur A, Michalowic ZB, Castillo M, Aeppli D. Interleukin-1 alpha, interleukin-8 and interferon-alpha levels in gingival crevicular fluid. J Periodontal Res 1996; 31: 489-5.

[23] Giannopoulo UC, Kamma J, Mombelli A. Effect of inflammation, smoking and stress on gingival crevicular fluid cytokine level. J Clin Periodontol 2003; 30: 145-53.

[24] Shearer B, Hall P, Clarke P, Marshall G, Kinane DF. Reducing variability and choosing ideal subjects for experimental gingivitis studies. J Clin Periodontol 2005; 32(7): 784-8.

[25] Loe H, Silness J. Periodontal disease in pregnancy. I. prevalence and severity. Acta Odont Scand 1963; 21: 533-51.

[26] Silness J, Loe H. Periodontal disease in pregnancy. II. correlation between oral hygiene and periodontal condition._Acta Odont Scand 1964; 22: 121-35.

[27] Hinrichs JL, Brandt CC, Smith JA. Relative error (variability) associated with an improved instrument for measuring gingival crevicular fluid. J Periodontol 1984; 55: 294-8.

[28] Mehta C, Patel R. Exact permutational inference for categorical and nonparametric data. In: Hoyle R, Ed. Statistical strategies for small sample research. Thousand Oaks: Sage Publications 1999; pp. 133-66.

[29] Tsiggos N, Tortopidis D, Hatzikyriakos A, Menexes G. Association between self-reported bruxism activity and occurrence of dental attrition, abfraction, and occlusal pits on natural teeth. J Prosth Dent 2008; 100: 41-6.

[30] Champagne ME, Buchanan W, Reddy M, Preisser JS, Offenbacher S. Potential for gingival crevice fluid measures as predictrors of risk for periodontal diseases. Periodontology 2000 2003; 31: 16780 .

[31] Jacoby R. Loess: a nonparametric, graphical tool for depicting relationships between variables. Electoral Stud 2000; 19: 577-613.

[32] Nyvad B. Tidlig bacteria eakkumulation pa emalje og rodoverflader in vivo. Sammenlignende ultrastructurelle og mikribiologiske undersogelser.Thesis Aarthus: Royal Dental College 1983.

[33] Holm-Pedersen P, Agerbaek N, Theilade E. Experimental gingivitis in young and elderly individuals. J Clin Periodontol 1975; 2: 14-24.

[34] Fransson C, Berglundh T, Lindhe J. The effect of age on the development of gingivitis. Clinical, microbiological and histological findings. J Clin Periodontol 1996; 23: 379-85.

[35] Berglundh T, Lindhe J. Gingivitis in young and old dogs. J Clin Periodontol 1993; 20(3): 179-85.

[36] Winkel EF, Abbas F, Hart AAM. Experimental gingivitisin relation to susceptibility to periodontal disease. J Clin Periodontol 1987; 14: 499-507.

[37] Zitzmann NU, Berglundh T, Marinello CP, Lindhe J. Experimental peri-implant mucositis in man. J Clin Periodontol 2001; 28: 51723. 
[38] Berglund T, Lindhe J. Gingivitis in young and adults dogs. J Clin Periodontol 2000; 20: 179-85.

[39] Lamster IB, Hartley LJ, Oshrain RL, Gordon JM. Evaluation and modification of spectrophotometric procedures for analysis of lactate dehydrogenase, beta-glucuronidase and arylsulphatase in human gingival crevicular fluid collected with filter-paper strips. Arch Oral Biol 1985; 30: 235-42.

[40] Ebenhard J, Ehlers H, Falk W, Acil Y, Albers HK, Jepsen S. Efficacy of subgingival calculus removal with Er: YAG laser compared to mechanical debridement: an in situ study. J Clin Periodontol 2003; 30(6): 511-8.

[41] Heasman SJ, Ridley AJ. Mammalian Rho GTPases: new insights into their functions from in vivo studies. Nat Rev Mol Cell Biol 2008; 9(9): 690-701.

[42] Zhang J, Kashket S, Lingstrom P. Evidence for the early onset of gingival inflammation following short-term plaque accumulation. $\mathrm{J}$ Clin Periodontol 2002; 29: 1082-5.

[43] Ohguchi Y, Ishihara Y, Ohguchi M, et al. Capsular polysaccharide from actinobacillus actinomytcetemcomitans inhibits IL-6 and IL-8 production in human gingival fibroblasts. J Periodontal Res 2003; 38: 190-7.

[44] Stromberg E, Edebo A, Lundin BS, et al. Down -regulation of epithelial IL-8 responses in Helicobacter pylori-infected duodenal ulcer patients depends on host factors, rather than bacterial factors. Clin Exp Immunol 2005; 140: 117-25.

[45] Marks DJB, Harbord MWN, MacAllister R, et al. Defective acute inflammation in chron's disease : a clinical investigation. Lancet 2006; 367: 668-78.

[46] Shearer B, Hall P, Clarke P, Marshall G, Kinane DF. Reducing variability and choosing ideal subjects for experimental gingivitis studies. J Clin Periodontol 2005; 32(7): 784-8.

[47] Celenligil-Nazliel H, Ayhan A, Uzun H, Ruacan S. The effect of age on proliferating cell nuclear antigen expression in oral gingival epithelium of healthy and inflamed human gingiva. J Periodontol 2000; 71(10): 1567-74.

[48] Siegel B, Weihe E, Bette M, Nusing RM, Flores-DE-Jocoby L, Mengel R. The effect of age on prostaglandin-synthesizing enzymes in the development of gingivitis. J Periodontal Res 2007; 42(3): 259-66.

[49] Mcgeer EG, Mcgeer PL. Innate immunity in Alzheimer's disease: a model for local inflammatory reactions. Mol Interv 2001; 1: 22-9.

[50] Tatakis DN, Trombelli L. Modulation of clinical expression of plaque induced gingivitis.I. Background review and rationale. J Clin Periodontol 2004; 31: 229-38.

[51] Goodson JM, Tanner AC, Haffajee AD, Sornberger GC, Soncransky SS. Patterns of progression and regression of advanced destructine periodontal disease. J Clin Periodontol 1982; 9: 472-81.

[52] Reuland-Bosma W, Van Dijk J, Van Der Weele L. Experimental gingivitis around deciduous teeth in children with Down's syndrome. J Clin Periodontol 1986; 13: 294-300.

[53] Preshaw PM, Geatch DR, Lauffart B, Jeffcoat MK, Taylor JJ, Heasman PA. Longitudinal changes in TCRB variable gene expression and markers of gingival inflammation in experimental gingivitis. J Clin Periodontol 1998; 25: 774-80.

[54] Jepsen S, Ebenhard J, Fricke D, Hedderich J, Siebert R, Acil Y. Interleukin -1gene plymorphisms and experimental gingivitis. J Clin Periodontol 2003; 30: 102-6.

[55] Scapoli C, Tatakis DN, Mamolini E, Trombelli L. Modulation of clinical expression of plaque-induced gingivitis: interleukin-1 gene cluster plymorphisms. J Periodontol 2005; 76: 49-56.
[56] Scapoli C, Mamolini E, Trombelli L. Role of IL-6, TNF-A and LTA variants in the modulation of the clinical expression of plaqueinduced gingivitis. J Clin Periodontol 2007; 34: 10381-8.

[57] Preshaw P. Host response modulation in periodontics. Periodontology 2000 2008; 48: 92-110.

[58] Hock J, Krishnan V, Onyia J, Bidwell J, Milas J, Stanislaus D. Osteoblast apoptosis and bone turnover. J Bone Mineral Res 2001; 16: $975-84$.

[59] Lang NP, Tonnetti MS. Periodontal risk assessment (PRA) for patients in supportive periodontal therapy. Oral Health Prev Dent 2003; 1: 7-16.

[60] Labriolla A, Needleman I, Moles D. Systematic review of the effect of smoking on nonsurgical periodontal therapy. Periodontology 2000 2005; 37: 124-37.

[61] Ryder MI, Pons B, Adams D, et al. Effect of smoking on local delivery of controlled -release doxycycline as compared to scaling and root planning. J Clin Periodontol 1999; 26: 683-91.

[62] Gonzalez YM, De Nardin A, Grossi SG, Machtei EE, Genco RJ. Serum nicotine levels, smoking and periodontal attachment loss. J Dent Res 1996; 75: 796-802.

[63] Brecx MC, Schegel K, Gehr P, Lang NP. Comparison between histological and clinical parameters during human experimental gingivitis. J Periodontal Res 1987; 22: 50-7.

[64] Page RC, Simpson D, Ammons W. Host tissue response in chronic inflammatory periodontal disease (IV).the periodontal and dental status of a group of aged great apes. J Periodontol 1975; 46: 14455 .

[65] Fransson C, Mooney T, Kinane DF, Berglundh T. Differences in the inflammatory response in young and old human subjects during the course of experimental gingivitis. J Clin Periodontol 1999; 26: 453-60.

[66] Chung RM, Grbic JT, Lamster IB. Interleukin 8 and b glucuronidase in gingival crevicular fluid. J Clin Periodontol 1997; 24: 14652 .

[67] Jin L, Wong KY, Leung WK, Corbet EF. Comparison of treatment response patterns following scaling and root planing in smokers and non-smokers with untreated adult periodontitis. J Clin Dent 2000; 11(2): 35-41.

[68] Ozmeric N, Bal B, Balos K, Berker E, Bulut S. The correlation of gingival crevicular fluid interleukin-8 levels and periodontal status in localized juvenile periodontitis. J Periodontol 1998; 69: 1299304.

[69] Tsai CC, Ho YP, Chen CC. Levels of interleukin-1b and interleukin-8 in gingival crevicular fluids in adult periodontitis. J Periodontol 1995; 66: 852-9.

[70] Gemmell E, Seymour GJ. Interleukin1, interleukin 6 and transforming growth factor-b production by human gingival mononuclear cells following stimulation with porphyromonas gingivalis and fusobacterium nucleatum. J Periodontal Res 1993; 28: 122-9.

[71] Seymour GJ, Gemmel E. Cytokines and periodontal disease: where to from here? Acta Odontol Scand 2001; 59: 167-73.

[72] Takigawa M, Takashiba S, Takahashi K, Arai H, Kurihara H, Murayama Y. Prostaglandin E2 inhibits interleukin- 6 release but not its transcription inhuman gingival fibroblasts stimulated with interleukin 1-b or tumor necrosis factor-a. J Periodontol 1994; 65: 1122 7.

[73] Okada H, Murakami S. Cytokine expression in periodontal health and disease. Crit Rev Oral Biol Med 1998; 9: 248-66.

[74] Kishimoto T. The biology of interleukin- 6. Blood 1989; 74: 1-10.

Received: May 04, 2009

(C) Lazaros Tsalikis; Licensee Bentham Open.

This is an open access article licensed under the terms of the Creative Commons Attribution Non-Commercial License (http://creativecommons.org/licenses/by-nc/3.0/) which permits unrestricted, non-commercial use, distribution and reproduction in any medium, provided the work is properly cited. 